\title{
Methods for Calculating Energy Requirements for Processes in Which a Reactant Is Also a Fuel: Need for Standardization
}

\author{
H.Y. SOHN ${ }^{1,2}$ and MIGUEL OLIVAS-MARTINEZ ${ }^{1}$ \\ 1.-Department of Metallurgical Engineering, University of Utah, Salt Lake City, UT 84112, \\ USA. 2.—e-mail: h.y.sohn@utah.edu
}

\begin{abstract}
When a process involves both endothermic chemical reactions and heat generation from the combustion of fuels, the choice of endothermic reactions to include in computing the "energy requirement" for the overall process is arbitrary and can be a source of confusion. It is shown that the essential question becomes whether the heat of combustion of a reactant, which can be used as a fuel, should be included in the energy requirement value. It is noted that the choice is a matter of convention, but it is important to clearly state what convention is followed in presenting the results of energy calculations. There is a need to select a standard approach because the presented value of "energy requirement" of a process depends on the choice. This problem is illustrated using the example of ironmaking by different processes including a novel flash ironmaking process under development at the University of Utah. The authors advocate using just the "process energy requirement" as the standard value of the energy requirement for a process in which a reactant is also a fuel.
\end{abstract}

\section{INTRODUCTION}

Different approaches are used for performing energy balance calculations and perhaps more significantly in presenting the "energy requirement" of a process. The question becomes more involved for a process in which one or more reactants are also used to generate the process heat by combustion. Often the key issue is which heat of the chemical reaction to include in computing (or presenting) the energy requirement of the process.

It is worthwhile to note at the outset that the difference in energy requirements between different processes for converting similar raw materials to the same desired product is largely unaffected by the choice of chemical reactions to be included. However, the absolute value presented as the energy requirement of a process can be different by a large amount depending on the approach. We will use the example of ironmaking processes to illustrate the problem. In these processes, as currently practiced or under development, carbon and/or hydrocarbons (including hydrogen) are used as the fuel as well as the reactant for reducing the iron oxide mineral.
The different approaches in this case essentially boil down to the following question: Does one include the combustion heat of the reductant used in the reduction reaction or treat the reductant portion as just a reactant? Depending on the viewpoint, either approach can be considered acceptable. It is a matter of convention. There is a need, however, to select a standard approach because the absolute value of the energy requirement of an ironmaking process (e.g., the currently dominant blast furnace process) depends on such a choice. It is particularly important to clearly state the specific approach used when the energy requirement of ironmaking is compared with those of other industrial processes such as petrochemicals production.

\section{ENERGY REQUIREMENT IN IRONMAKING PROCESSES}

\section{General Energy Balance and Total Energy Requirement}

To determine the energy requirement of a steadystate process, we start from the general statement of energy balance: 


$$
\begin{aligned}
& \left\{\begin{array}{r}
\text { Energy Input } \\
\text { with Input Streams }
\end{array}\right\}-\left\{\begin{array}{r}
\text { Energy Output } \\
\text { with Output Streams }
\end{array}\right\} \\
& +\left\{\begin{array}{r}
\text { Energy Generation } \\
\text { within System }
\end{array}\right\} \mp\left\{\begin{array}{r}
\text { Energy Leaving } \\
\text { or Added to System }
\end{array}\right\} \\
& =0
\end{aligned}
$$

Mathematically,

$$
\begin{aligned}
& \left(-\Delta H_{T_{\mathrm{r}}}^{\prime}\right)+\sum_{i} n_{i}\left(H_{T}-H_{T_{\mathrm{r}}}\right)_{i} \\
& \quad=\sum_{j} n_{j}\left(H_{T}-H_{T_{\mathrm{r}}}\right)_{j}+Q_{\text {loss }}+Q_{\text {recovered }}
\end{aligned}
$$

where $n_{i}$ and $n_{j}$ denote the amounts of the $i$ th reactant and the $j$ th product, respectively, and $\left(H_{T}-H_{T_{r}}\right)$ is the sensible enthalpy of a given species at the system temperature $(T)$. The first term on the left-hand side (LHS) of Eq. 2 represents the total enthalpy of reactions occurring in the system at the reference temperature $\left(T_{\mathrm{r}}\right)$. When the overall chemical reaction is exothermic, this term is positive (i.e., energy input to the system). The opposite is true for overall endothermic reactions. In an ironmaking process, this term is positive because energy is added to the system by the combustion of fuels.

The second term in the LHS of Eq. 2 is the energy added to the system in the form of sensible heat of the reactants. (If the reactants enter the system at the reference temperature, this term is zero.) The first term on the right-hand side (RHS) represents the energy removed from the system in the form of sensible heat in the products. The second term on the RHS is the energy removed from the system in the form of heat losses to the surroundings from the process. The last term in the RHS is the recoverable heat from the process (e.g., recovery of sensible heat of the off-gases). When some products contain a fuel value, it should be included in this term.

For a process involving chemical reactions to produce useful products and combustion of fuels to generate process heat, the total reaction enthalpy is a sum of the two general terms shown in the following equation:

$$
\left(-\Delta H_{T_{\mathrm{r}}}^{\prime}\right)=\left(-\Delta H_{T_{\mathrm{r}}}^{\prime}\right)_{\text {reaction }}+\left(-\Delta H_{T_{\mathrm{r}}}^{\prime}\right)_{\text {combustion }}
$$

where $\left(-\Delta H_{T_{r}}^{\prime}\right)_{\text {reaction }}$ is the heat of reaction that is usually endothermic (negative term) for a process that has a "heat requirement" and $\left(-\Delta H_{T_{\mathrm{r}}}^{\prime}\right)_{\text {combustion }}$ is the combustion heat (positive term) of the fuel used to generate process heat. Substituting Eq. 3 into Eq. 2, the energy balance becomes

$$
\begin{aligned}
\left(-\Delta H_{T_{\mathrm{r}}}^{\prime}\right)_{\text {combustion }}+\sum_{i} n_{i}\left(H_{T}-H_{T_{\mathrm{r}}}\right)_{i} \\
=\left(\Delta H_{T_{\mathrm{r}}}^{\prime}\right)_{\text {reaction }}+\sum_{j} n_{j}\left(H_{T}-H_{T_{r}}\right)_{j} \\
+Q_{\text {loss }}+Q_{\text {recovered }}
\end{aligned}
$$

To calculate and compare energy requirements of different processes to produce the same desired product, the system boundaries for the different processes should be drawn so that all input materials enter the system at the reference temperature (i.e., $298 \mathrm{~K}$ ). Thus, the second term on the LHS of Eq. 4 is zero. The "total energy requirement" is then given by the following equation, taking into consideration that $Q_{\text {recovered }}$ is credited to decrease the energy requirement either by preheating some of the input stream or simply recovered as a useful energy source. The energy requirement is then given by

Energy Requirement

$$
\begin{aligned}
& =\left(-\Delta H_{T_{\mathrm{r}}}^{\prime}\right)_{\text {combustion }}-Q_{\text {recovered }} \\
& =\left(\Delta H_{T_{\mathrm{r}}}^{\prime}\right)_{\text {reaction }}+\sum_{j} n_{j}\left(H_{T}-H_{T_{\mathrm{r}}}\right)_{j}+Q_{\text {loss }}
\end{aligned}
$$

This equation assumes that the sensible heat contained in the products is unrecoverable and thus is discarded.

In ironmaking processes, the choice of endothermic reactions, i.e., $\left(-\Delta H_{T_{\mathrm{r}}}^{\prime}\right)_{\text {reaction, }}$, to include in computing the total energy requirement (Eq. 5) for the overall process is arbitrary and can be a source of confusion. In the following sections, the choice of the endothermic reactions on the resulting energy requirement is discussed and two approaches for calculating the energy requirement are described.

\section{Definitions of Chemical Energy Terms}

To reduce iron oxides to iron, the energy requirement for the reduction reaction can be defined in two ways: One is to consider the reduction as decomposing iron oxide to iron and oxygen (reverse of the energy of formation of iron oxide); the other is to consider it as a reaction of iron oxide with a reductant. (As shown below, the former is equivalent to including the heat of combustion of the fuel/ reductant acting as a reductant in the total energy requirement, whereas the latter is equivalent to not including it.) The following is a simplified demonstration of these equivalences.

The demonstration is made just for the energy involved with chemical changes at a reference temperature (usually $298 \mathrm{~K}$ ), excluding sensible heat and other energy terms (see Eq. 5), which do not affect the argument discussed here.

\section{Basis of the Simplified Demonstration}

1. The solid charge is composed of pure iron oxide. No flux materials are considered.

2. Carbon is used as the fuel/reductant. However, this methodology can easily be extended to the case in which hydrogen or a hydrocarbon is used as the fuel/reductant.

3. The total carbon input is divided into two groups: fuel carbon and reductant carbon. 
4. The heat balance is performed over the entire system. The process outputs are iron and the complete combustion product $\left(\mathrm{CO}_{2}\right)$ of fuel carbon plus the reduction product $\left(\mathrm{CO}_{2}\right)$, all at $298 \mathrm{~K}$.

\section{Chemical Reactions}

The overall chemical reaction taking place to reduce iron oxide to iron using carbon as the fuel/reductant is

$$
\begin{aligned}
& {\left[\mathrm{Fe}_{3} \mathrm{O}_{4}+2(\mathrm{C})_{\mathrm{r}}\right]+\left[x(\mathrm{C})_{\mathrm{f}}+x\left(\mathrm{O}_{2}\right)_{\mathrm{f}}\right]} \\
& \quad=3 \mathrm{Fe}+2\left(\mathrm{CO}_{2}\right)_{\mathrm{r}}+x\left[\mathrm{CO}_{2}\right]_{\mathrm{f}}
\end{aligned}
$$

where $(\mathrm{C})_{\mathrm{r}}$ is the carbon consumed by the reduction reaction, $(\mathrm{C})_{\mathrm{f}}$ is the carbon burned to generate heat, $\left(\mathrm{O}_{2}\right)_{\mathrm{f}}$ is the oxygen for reaction with the fuel carbon, $\left(\mathrm{CO}_{2}\right)_{\mathrm{r}}$ is the carbon dioxide produced by the reduction reaction, $\left(\mathrm{CO}_{2}\right)_{\mathrm{f}}$ is the carbon dioxide produced by combustion of the fuel carbon, and $x$ is the number of moles of the fuel portion of carbon required to generate the heat for the reduction process.

The enthalpy change of the overall reaction (Eq. 6) is a combination of the energy required to reduce iron oxide and the energy produced by combustion of the fuel/reductant. As mentioned in the Introduction, different definitions of "energy requirement" are possible depending on what one considers the reduction reaction between the following two reactions:

$$
\mathrm{Fe}_{3} \mathrm{O}_{4}=3 \mathrm{Fe}+2\left(\mathrm{O}_{2}\right)_{\mathrm{r}}
$$

and

$$
\mathrm{Fe}_{3} \mathrm{O}_{4}+2(\mathrm{C})_{\mathrm{r}}=3 \mathrm{Fe}+2\left(\mathrm{CO}_{2}\right)_{\mathrm{r}}
$$

\section{Approach 1: Energy Requirement for Reduction Reaction Based on Oxide Decomposition}

When the reduction of iron oxide is considered to be the decomposition of the iron oxide (Eq. 7), the energy requirement for the reduction process is the difference between the heats of Eqs. 6 and 7, which is equivalent to the heat of the following combustion reaction:

$$
\begin{aligned}
& {\left[2(\mathrm{C})_{\mathrm{r}}+x(\mathrm{C})_{\mathrm{f}}\right]+\left[2\left(\mathrm{O}_{2}\right)_{\mathrm{r}}+x\left(\mathrm{O}_{2}\right)_{\mathrm{f}}\right]} \\
& \quad=\left[2\left(\mathrm{CO}_{2}\right)_{\mathrm{r}}+x\left(\mathrm{CO}_{2}\right)_{\mathrm{f}}\right]
\end{aligned}
$$

The heat of this reaction $\left[\left(-\Delta H_{T_{r}}^{\prime}\right)_{\text {combustion }}\right]$ corresponds to the chemical heating value of the total amount of carbon supplied to the system. Several reports $^{1-3}$ on energy use in the ironmaking industry follow this approach.

\section{Approach 2: Energy Requirement Based on Oxide Reaction with Reductant}

When the reduction of iron oxide is considered as the reaction of iron oxide with carbon (Eq. 8), the energy requirement for the reduction process is the difference between the heats of Eqs. 6 and 8, which is equivalent to the heat of the following combustion reaction:

$$
x(\mathrm{C})_{\mathrm{f}}+x\left(\mathrm{O}_{2}\right)_{\mathrm{f}}=x\left(\mathrm{CO}_{2}\right)_{\mathrm{f}}
$$

The heat of this combustion reaction $\left[\left(-\Delta H_{T_{\mathrm{r}}}^{\prime}\right)_{\text {combustion }}\right]$ corresponds to the chemical heating value of just the fuel portion of carbon $(\mathrm{C})_{\mathrm{f}}$. Some energy balance calculations ${ }^{4-6}$ have used this approach.

\section{RESULTS}

The application of the above two approaches to the calculation of the energy requirement is illustrated using as an example a novel flash ironmaking process under development at the University of Utah and an average blast furnace operation. As part of this development work, Pinegar et al. ${ }^{5}$ prepared a material and energy flow diagram for a commercial-scale reformerless flash ironmaking process producing 1 million tonnes of iron per year and operating with natural gas using the commercially available software METSIM.

\section{Material and Energy Flows: System Boundary}

Energy balance calculations start with a material balance around a clearly defined system boundary. A system boundary can be drawn around different parts of a process, depending on the purpose of the calculation. An illustration is given in Fig. 1. The solid lines represent material flow with associated sensible and latent heats, and the open arrows indicate the flow of heat only. Once the boundary is defined, any open-ended streams that cross it are the input and output streams. Any streams entirely inside a boundary (e.g., the off-gas in Fig. 1 in the case of the outer boundary) are not included in the balance calculations around that boundary.

Often the definition of the system boundary is not clearly stated in previous reports. This shortcoming was faced by the authors when they reviewed the literature, especially for the blast furnace process. Without this piece of information, it is difficult to compare the energy requirements of different processes. In the ironmaking industry, Battle and McClelland ${ }^{7}$ have also recognized this problem and advocate clearly defining the input and output streams and conditions in energy balance calculations.

It is noted that the heat contents of any output streams that can be recovered for a useful purpose, such as steam, should be credited to reduce the input amount of energy or "energy requirement." This is equivalent to placing that term as a negative input item in the energy balance (Eq. 5). Heat losses and the sensible heat of an output stream that are not recovered are output items and increase the 


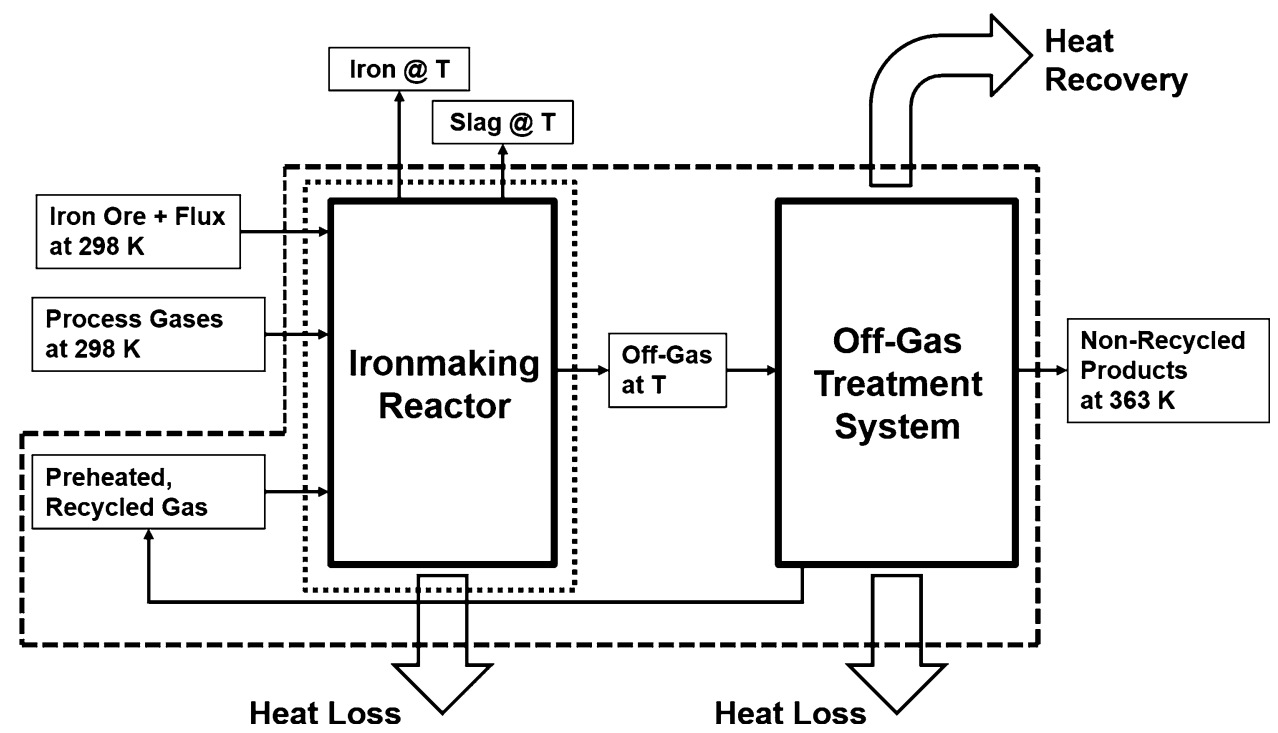

Fig. 1. Examples of system boundaries for material and energy balance calculations for an ironmaking process.

Table I. Energy input items for a commercial-scale flash ironmaking process using natural gas or hydrogen compared with those for an average blast furnace process (production rate $=1$ million tonnes of iron per year at $1773 \mathrm{~K}$ (300 days of operation in 1 year).) Adapted from Pinegar et al. ${ }^{4,5}$

\begin{tabular}{|c|c|c|c|c|c|c|c|}
\hline \multicolumn{2}{|r|}{ Process } & \multicolumn{2}{|c|}{$\begin{array}{l}\text { Reformer- } \\
\text { less natural } \\
\text { gas } \\
\end{array}$} & \multicolumn{2}{|c|}{ Hydrogen $^{\text {a }}$} & \multicolumn{2}{|c|}{$\begin{array}{l}\text { Blast fur- } \\
\text { nace }^{b, c}\end{array}$} \\
\hline \multirow{4}{*}{ Itemized input (GJ/t Fe) } & Approach & $\mathbf{1}$ & 2 & $\mathbf{1}$ & 2 & $\mathbf{1}$ & 2 \\
\hline & $\begin{array}{c}\text { Fuel combustion }{ }^{\mathrm{d}} \\
\text { Heat recovery (sum of next 2) } \\
\text { Waste heat boiler } \\
\text { Steam not used }\end{array}$ & \multicolumn{2}{|c|}{$\begin{array}{l}-4.77 \\
-3.39 \\
-1.38\end{array}$} & \multicolumn{2}{|c|}{-2.80} & \multicolumn{2}{|c|}{-1.32} \\
\hline & $\begin{array}{c}\text { Sub-total } \\
\text { Ore/coke preparation }\end{array}$ & 14.45 & & 11.25 & 5.48 & \multicolumn{2}{|c|}{5.68} \\
\hline & $\begin{array}{c}\mathrm{CaCO}_{3} \text { and } \mathrm{MgCO}_{3} \text { calcination (external) } \\
\text { Total }\end{array}$ & 0.26 & & & 5.74 & 17.96 & 12.69 \\
\hline \multicolumn{8}{|c|}{$\begin{array}{l}\text { aThe energy requirement for hydrogen production was not included for this calculation. It is anticipated that the energy required for } \\
\text { hydrogen production will strongly depend on the production process such as steam-methane reforming, coal gasification, or water } \\
\text { splitting. } \\
\text { bEnergy balance was calculated by METSIM based on the published material balance. } \\
\text { 'In fairness to excluding the energy requirement of hydrogen production in the energy balance of flash ironmaking, the energy required } \\
\text { for producing coking coal was not included either for the blast furnace. } \\
\text { dFuel combustion energy input was calculated by adding the energy (subtracting reaction enthalpy) for iron ore reduction from the } \\
\text { difference of heats of formation of all output components and input components (Eq. } 6 \text { ). This amount is equivalent to the heat of Eq. } 9 \text { for } \\
\text { Approach } 1 \text { and Eq. } 10 \text { for Approach } 2 \text {. HHVs of the natural gas and hydrogen were used for this calculation. } \\
\text { eFrom Fruehan et al. }{ }^{2} \text { and Stubbles. }\end{array}$} \\
\hline
\end{tabular}

input amount and, thus, the energy requirement. Furthermore, all heats of a chemical reaction (chemical heat contents), including heat of combustion, are calculated at $298 \mathrm{~K}$ and all sensible heat in input or output streams is calculated relative to this temperature.

\section{Energy Balances for Ironmaking Processes}

Tables I and II present energy inputs and outputs, respectively, in terms of Approaches 1 and 2 for the flash ironmaking process using natural gas or hydrogen and for the average blast furnace operation. The annual production rates in all the cases are 1 million tonnes of iron from a single unit of the ironmaking reactor. The energy balance for the flash ironmaking process is based on the flow sheet presented by Pinegar et al. ${ }^{5}$ Higher heating values (HHVs) of natural gas and hydrogen were used to be conservative in calculating the energy requirements, respectively, of reformerless flash ironmaking and hydrogen-based flash ironmaking. 
Table II. Energy output items for a commercial-scale flash ironmaking process using natural gas or hydrogen compared with those for an average blast furnace process (production rate $=1$ million tonnes of iron per year at $1773 \mathrm{~K}$ (300 days of operation in 1 year).) Adapted from Pinegar et al. ${ }^{4,5}$

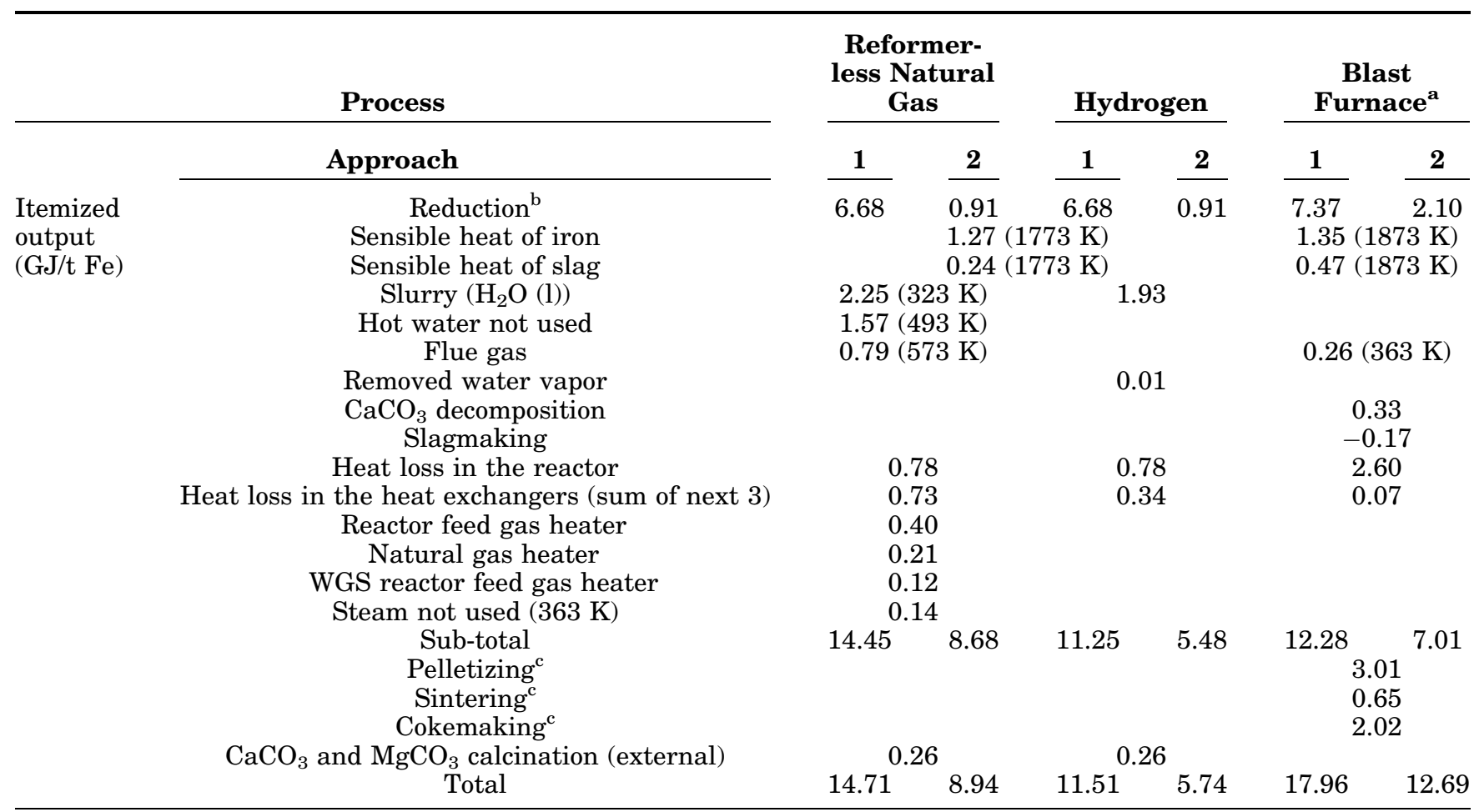

${ }^{\mathrm{a}}$ Energy balance was calculated by METSIM based on the published material balance.

${ }^{\mathrm{b}}$ For the flash ironmaking process, the reduction energy corresponds to the decomposition of magnetite (Eq. 7) (6.68 GJ/t Fe) for Approach 1. For the blast furnace, it corresponds to the heat of decomposition of $\mathrm{Fe}_{2} \mathrm{O}_{3}(7.37 \mathrm{GJ} / \mathrm{t} \mathrm{Fe})$. In Approach 2, reduction energy corresponds to the heat of the reduction reaction $(0.91 \mathrm{GJ} / \mathrm{t} \mathrm{Fe})$ for flash ironmaking and the heat of the reaction $\mathrm{Fe}_{2} \mathrm{O}_{3}+3 / 2 \mathrm{C}=2 \mathrm{Fe}+3 / 2 \mathrm{CO} \mathrm{O}_{2}$ for the blast furnace. (See discussion in the text for the justification of using hematite for the blast furnace.)

${ }^{\mathrm{c}}$ From Fruehan et al. ${ }^{2}$ and Stubbles. ${ }^{3}$

The energy balance for an average blast furnace operation was calculated using published material balance data and applying the same method of calculating energy values as for the flash ironmaking process.

Furthermore, the energy balances for the reformerless flash ironmaking process and for the average blast furnace are illustrated in Fig. 2 as Sankey diagrams. ${ }^{10}$ The energy balances represented by these Sankey diagrams as well as by Tables I and II were calculated around the outer boundary in Fig. 1, depicted by the dashed line. In a Sankey diagram, the width of each energy stream is proportional to the magnitude of its energy quantity which, in this work, corresponds to energy flow (GJ/ $\mathrm{t} \mathrm{Fe}$ ). In addition, Sankey diagrams showing the energy flows on the individual unit processes and operations, including internal recycle streams, can be constructed. An example of such a diagram for the reformerless flash ironmaking under Approach 1 is presented in Fig. 3. In this diagram, the energy flows by internal recycle streams as well as their magnitudes can clearly be seen. This comprehensive version of the Sankey diagram was prepared just for the case of reformerless flash ironmaking because the detailed internal steps for the blast furnace process were not considered in this work.

In the blast furnace process, the energy consumed by sintering, pelletizing, and cokemaking operations, which are not required in flash ironmaking, is part of the energy requirement and represents a significant portion of the overall energy requirement for the blast furnace operation. The ore/coke preparation accounts for $30-40 \%$ of the total energy input (which is defined as the sum of the input streams) in terms of Approaches 1 and 2, respectively, as can be seen in Fig. 2.

For the flash ironmaking process, the cases of using two different reductants/fuels, natural gas or hydrogen, have been analyzed. The results of applying Approach 2 were adapted from Pinegar et al. ${ }^{4,5}$ and those of applying Approach 1 were calculated by modifying the "Fuel combustion" term in the input category and the "Reduction" term in the output category, which are the only numbers that are different between Approaches 1 and 2. 


\section{Reformerless Natural Gas}
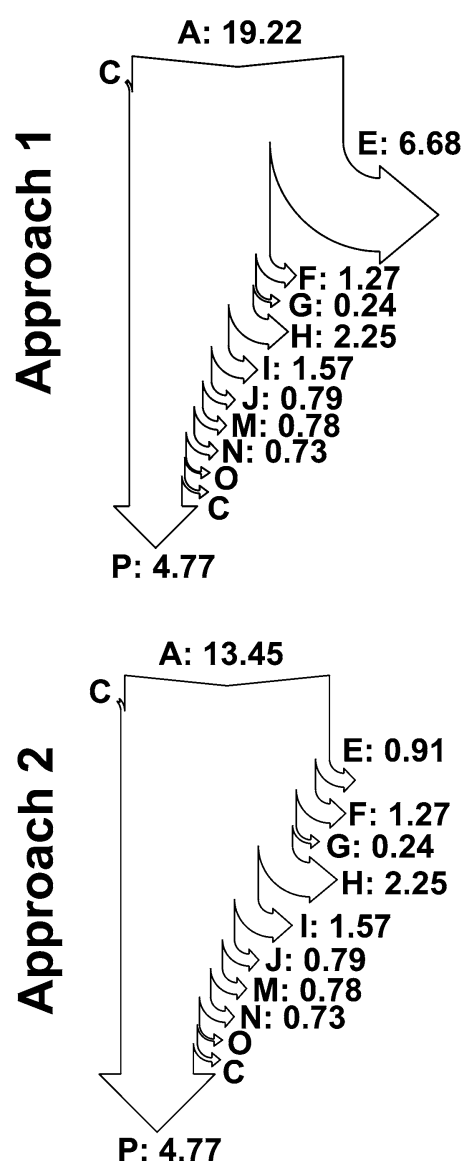

Hydrogen Blast Furnace

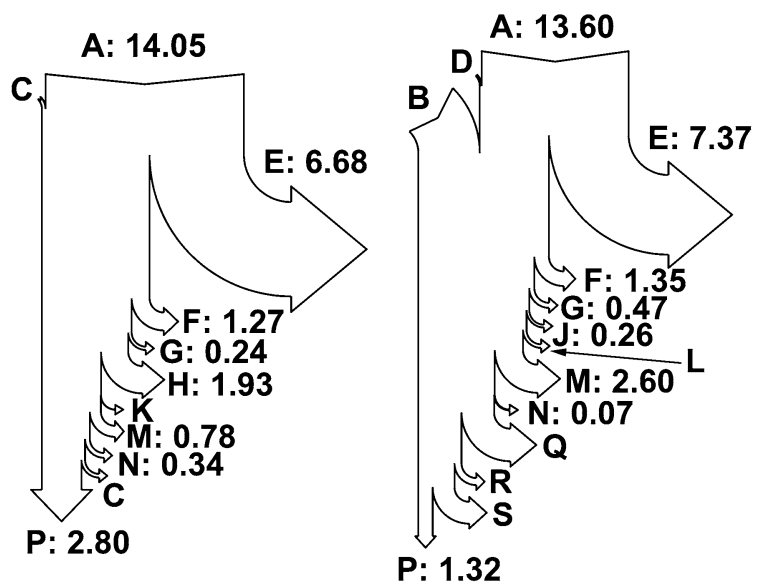

A: 8.28

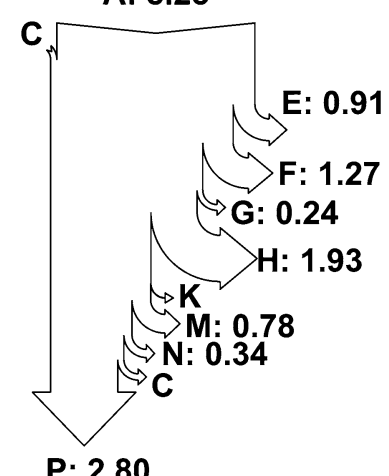

P: 2.80

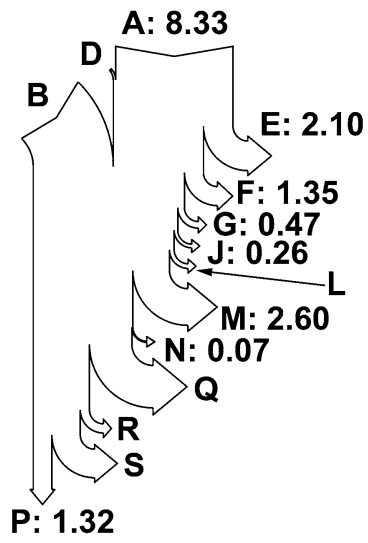

Fig. 2. Sankey diagrams for reformerless flash ironmaking and average blast furnace. Prepared with MATLAB ${ }^{8}$ using the function drawSankey. ${ }^{9}$ Values in GJ/t Fe. Input energy flows: $A$ fuel combustion, $B$ coke/ore preparation (5.68), $C$ calcination (0.26), $D$ slagmaking (0.17). Output energy flows: $E$ reduction, $F$ sensible heat of iron, $G$ sensible heat of slag, $H$ slurry, $I$ hot water not used, $J$ flue gas, $K$ removed water vapor $(0.01), L$ $\mathrm{CaCO}_{3}$ decomposition (0.33), $M$ heat loss in ironmaking reactor, $N$ heat loss in heat exchangers, $O$ steam not used $(0.14), P$ heat recovery, $Q$ pelletizing (3.01), $R$ sintering (0.65), $S$ cokemaking (2.02).

In terms of the descriptions of Approaches 1 and 2 formulated above, the "fuel combustion" energy input was calculated by adding the energy (subtracting reaction enthalpy) for iron ore reduction from the difference of heats of formation of all output components and input components (Eq. 6). This amount is equivalent to the heat of combustion of Eq. 9 for Approach 1 and Eq. 10 for Approach 2.

The "reduction" energy in the output category (i.e., Table II) corresponds to the decomposition of magnetite $\left(\mathrm{Fe}_{3} \mathrm{O}_{4}\right)$ [(Eq. 7) $(6.68 \mathrm{GJ} / \mathrm{t} \quad \mathrm{Fe})$ ] for Approach 1 for the flash ironmaking process. For the blast furnace, it corresponds to the heat of decomposition of hematite $\left(\mathrm{Fe}_{2} \mathrm{O}_{3}\right)(7.37 \mathrm{GJ} / \mathrm{t} \mathrm{Fe})$. (Magnetite concentrate must be pelletized or sintered to be used in a blast furnace during which it is converted to hematite, generating heat. This heat generation is reflected in the energy requirement for pelletization. Thus, it is appropriate to use hematite as the feed material in blast furnace operations.) In
Approach 2, the reduction energy corresponds to the heat of reduction reaction by hydrogen $(0.91 \mathrm{GJ} / \mathrm{t}$ $\mathrm{Fe}$ ) for flash ironmaking. (Even when natural gas is used, essentially all reduction is done by hydrogen produced from partial combustion of natural gas.) For the blast furnace, it is the heat of the reaction $\mathrm{Fe}_{2} \mathrm{O}_{3}+3 / 2 \mathrm{C}=2 \mathrm{Fe}+3 / 2 \mathrm{CO}_{2}$.

The energy requirement calculated using Approach 2 is the "process energy requirement," and the difference between the total input energy by Approach 1 and the process energy requirement may be termed "reductant energy" ("feedstock energy" in petrochemicals production). ${ }^{11}$

\section{DISCUSSION}

As shown in Tables I and II and Fig. 2, the difference in the energy requirements between each ironmaking process and the blast furnace remains largely the same regardless of the treatment given to the fuel used as a reductant. 


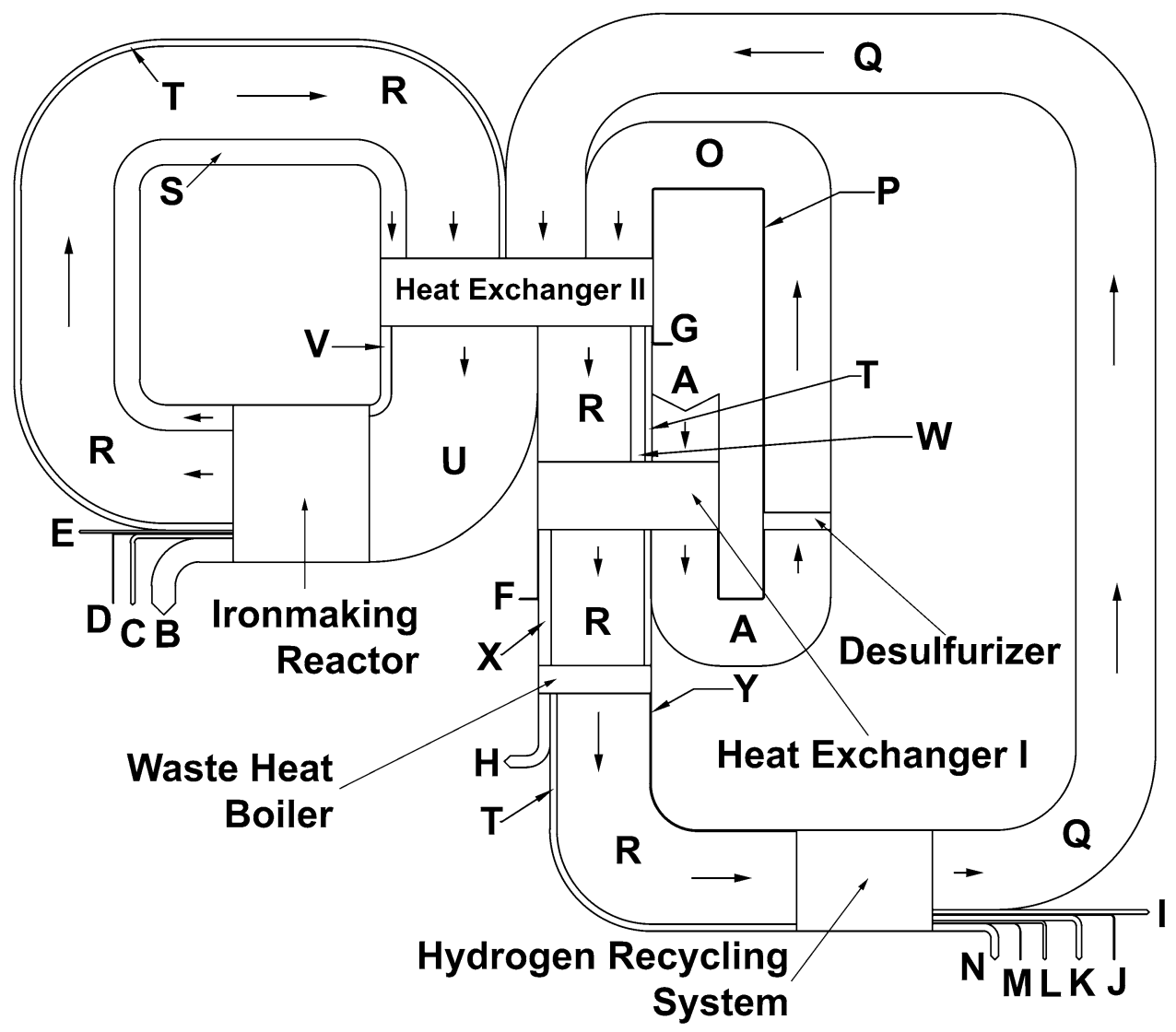

Fig. 3. Sankey diagram based on Approach 1 for a commercial-scale reformerless flash ironmaking process producing 1 million tonnes of iron per year at $1773 \mathrm{~K}$ (300 days of operation in 1 year). Prepared from data presented in Pinegar et al. ${ }^{5}$ Values in GJ/t Fe. Input energy flows: $A$ fresh natural gas (19.22). Output energy flows: $B$ reduction (6.68), $C$ sensible heat of iron (1.27), $D$ sensible heat of slag (0.24), $E$ heat loss in ironmaking reactor (0.78), $F$ heat loss in heat exchanger I (0.21), $G$ heat loss in heat exchanger II $(0.39), H$ waste heat boiler (3.39), I exported steam vaporization heat (1.24), $J$ exported steam sensible heat $(0.27), K$ hot water not used $(1.57), L$ flue gas $(0.79), M$ heat loss in hydrogen recycling system (0.12), $N$ slurry (2.25). Internal energy flows: $O$ desulfurized natural gas HHV (19.22), $P$ desulfurized natural gas sensible heat (0.36), $Q$ recycled hydrogen (23.46), $R$ off-gas HHV (27.41), $S$ off-gas sensible heat (7.53), $T$ water in off-gas vaporization heat (2.04), $U$ preheated feed gas HHV (43.02), $V$ preheated feed gas sensible heat (3.25), $W$ off-gas sensible heat (4.24), $X$ off-gas sensible heat (3.68), $Y$ offgas sensible heat $(0.29)$.

The "energy requirements" of these processes can be obtained directly from the total amounts of energy inputs in Table I and outputs in Table II. This is possible because in Table I the recovered heat is presented as a negative input item, as indicated by Eq 5. The energy balance results can be presented with such an item listed as a positive output item in Table II. This is actually how the recovered heat is presented in the Sankey diagrams shown in Fig. 2; in which case, the "balance" is still achieved, as indicated by Eq. 4 .

In some reports, ${ }^{2,12}$ the energy required for decomposing iron oxide to iron and oxygen, Eq. 7, is used as the "theoretically lowest" or "theoretical minimum" energy requirement. It is noted that this reaction, which does not actually take place under ironmaking processes, involves the largest enthalpy change (energy requirement) of any chemical reactions involved in the production of iron from iron oxide. As illustrated by the Sankey diagrams
(Fig. 2) for Approach 1, this decomposition reaction requires (energy output) more than $30 \%$ of the energy input in both processes. The energy required for this reaction is used as an item of energy requirement in Approach 1 above. In Approach 2, the endothermic heat of the reduction reaction (Eq. 8) is used for calculating the energy requirement. This energy represents only $7 \%$ and $15 \%$ of the energy input when Approach 2 is used for determining the energy requirement for the flash ironmaking process and blast furnace, respectively.

A simple food-for-thought question: If we consider a process in which the reaction

$$
2 / 3 \mathrm{Fe}_{2} \mathrm{O}_{3}+\mathrm{C}=4 / 3 \mathrm{Fe}+\mathrm{CO}_{2}
$$

occurs at room temperature, what do we consider as the energy requirement for the process? Is it the heat of Eq. 11, or should it include the heat of combustion of the carbon used as a reactant just because it has a heating value? 


\section{CONCLUSION}

When calculating energy requirements and presenting the results, it is essential to clearly state the approach used. Specifically and most importantly, it should be stated despite whether the chemical heat content (the heat of combustion) of a reactant that can also be used as a fuel is included in the calculated value of energy requirement. Even with these clarifications of approaches, it will make it much clearer to present distinct values for the process energy requirement that includes only the heating value of the fuel and reductant energy (feedstock energy in petrochemicals production) that represents the chemical heating value of the material used as a reactant.

The authors advocate using just the process energy requirement as the standard value of the energy requirement for a process in which a reactant is also a fuel, which is equivalent to using Approach 2.

In addition, a statement regarding whether the HHV (assumes liquid water in the combustion products) or the lower heating value (assumes water vapor in the combustion products at $298 \mathrm{~K}$ ) should be included when the fuel contains hydrogen. Another item of information often neglected that must be provided is the system boundary around which the material and energy balances are performed; that is, clear definitions of input and output streams and conditions.

\section{ACKNOWLEDGEMENTS}

The authors thank Dr. D. R. Forrest, Technology Manager, Advanced Manufacturing Office, U.S. Department of Energy, for raising the issues regarding differences in calculating energy requirements for different ironmaking processes. We also thank J. Cresko of DOE for suggesting that we prepare a written record of this issue. This material contains results of work supported by the U.S. Department of Energy under Award Number DE-EE0005751.

\section{REFERENCES}

1. R. Remus, M.A. Aguado Monsonet, S. Roudier, and L. Delgado Sancho, Best Available Techniques (BAT) Reference Document for Iron and Steel Production. Industrial Emissions Directive 2010/75/EU (Integrated Pollution Prevention and Control), Joint Research Centre (JRC) of the European Union: Spain, 2013, pp. 304-305.

2. R.J. Fruehan, O. Fortini, H.W. Paxton, and R. Brindle, Theoretical Minimum Energies to Product Steel for Selected Conditions, March 2000, U.S. Department of Energy, http:// www1.eere.energy.gov/industry/steel/pdfs/theoretical_mini mum_energies.pdf (accessed April 30, 2011).

3. J. Stubbles, Energy Use in the U.S. Steel Industry: An Historical Perspective and Future Opportunities, September 2000, U.S. Department of Energy, http://www1.eere.energy. gov/manufacturing/resources/steel/pdfs/steel_energy_use.pdf (accessed September 17, 2013).

4. H.K. Pinegar, M.S. Moats, and H.Y. Sohn, Steel Res. Int. 82, 951 (2011).

5. H.K. Pinegar, M.S. Moats, and H.Y. Sohn, Ironmak. Steelmak. 39, 398 (2012).

6. J.A. Burgo, The manufacture of pig iron in the blast furnace.The Making, Shaping and Treating of Steel, 11th ed., ed. D.H. Wakelin (Pittsburgh, PA: The AISE Steel Foundation, 1999), pp. 712-713.

7. T.P. Battle and J.M. McClelland, AISTech 2011 Proceedings 1, 943 (2011).

8. The MathWorks, Inc., MATLAB version 7.10.0, Natick, MA, (2010).

9. J. Spelling, drawSankey (http://www.mathworks.com/ matlabcentral/fileexchange/26573-drawsankey), MATLAB Central File Exchange, (2009) (accessed April 29, 2014).

10. M.E. Schlesinger, Mass and Energy Balances in Materials Engineering (Upper Saddle River: Prentice-Hall Inc., 1996), pp. 229-233.

11. N. Santero, Feedstock Energy in Bitumen, http://www.ucprc. ucdavis.edu/P-LCA/pdf/04_feedstock_web.pdf (accessed May 7, 2013).

12. J. de Beer, E. Worrell, and K. Blok, Annu. Rev. Energy 23, $123(1998)$ 